\title{
Operadores de caldeira à lenha e a exposição ao calor
}

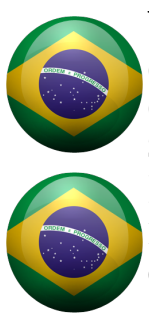

\section{Vilson Bernardo Stollmeier}

Coordenador e Professor de Pós Graduação em Engenharia de Segurança do Trabalho na Universidade de Cuiabá. Mestrado em Projeto de Produto. Engenheiro Industrial Mecânico, Especialista em Engenharia de Segurança do Trabalho. Rondonópolis [MT] Brasil < vilson.stollmeier@hotmail.com>.

\section{Ivan de Oliveira}

Docente do Curso de Pós-Graduação em Engenharia de Segurança do Trabalho das Faculdades Integradas de Rondonópolis, Universidade de Cuiabá. Rondonópolis [MT] Brasil <ikjoliveira@yahoo.com.br>.

\section{Resumo}

Este artigo apresenta uma análise da exposição ao calor do trabalho no setor de caldeira à lenha de uma empresa do setor industrial, com foco na análise da carga ambiental da atividade. Para tanto, os procedimentos metodológicos consistiram na análise documental, entrevistas, filmagens, avaliação de problemas dos efeitos do ambiente quente e sua prevenção. Os resultados mostram que os operadores de caldeiras à lenha estão expostos ao calor e precisam de orientações sobre suas atividades diárias com prevenções de doenças afetadas pelo excesso de calor. Também são sugeridos treinamentos na área técnica e de saúde para melhoria das condições de trabalho e da saúde do operador.

\section{Palavras-chave}

Exposição ao calor. Ambiente do trabalho. Caldeira à lenha.

\section{Firewood boiler operators and heat exposure}

\begin{abstract}
This article presents an analysis of heat exposure work in boiler industry wood from a company in the industrial sector, focusing on the analysis of the environmental burden of the activity. Therefore, the methodological procedures consisted of document analysis, interviews, filming, evaluation problems of the effects of the hot environment and its prevention. The results show that the fuel to the boiler operators are exposed to heat and need guidance on their daily activities with prevention of diseases affected by excessive heat. Are also suggested training in technical and health to improve working conditions and the operator's health.
\end{abstract}

\section{Keywords}

Exposure to heat. Environmental work. Boiler to firewood. 


\section{Introdução}

Os fatores ambientais que afetam a saúde do trabalhador, quando exposto ao calor excessivo em sua área de trabalho, são: temperatura, umidade, calor radiante (como o que provém do sol ou de um forno) e a velocidade do ar. As características pessoais são talvez o fator que mais pesa durante a exposição ao calor. Entre elas, destacam-se a idade, o peso, as condições físicas e orgânicas e a aclimatação ao calor (INFOSEG, Edição 101). Sendo assim, a liberação do calor do corpo consiste no aumento da circulação sanguínea na pele e aumento de temperatura do mesmo.

Para o efeito do ambiente quente pode-se dizer que: [...]

[...] durante exercícios físicos violentos, liberta-se calor da atividade muscular, o qual é distribuído por todas as partes do corpo através do sangue, provocando uma subida de temperatura corporal. Os capilares da pele dilatam-se para que a maior quantidade de sangue possa ser trazida à superfície, perdendo calor. Este aporte de sangue à periferia faz com que a pessoa fique vermelha e afogueada. As glândulas sudoríparas segregam mais suor que se evapora e arrefece o corpo. A frequência ventilatória aumenta e é libertada pelos pulmões uma maior quantidade de calor. A permanência da pessoa em ambiente quente pode provocar duas situações: golpe de calor e insolação (Cruz Vermelha Portuguesa, 1999, p. 80).

0 calor afeta, normalmente, as pessoas que fazem exercícios físicos ou trabalhos em ambientes quentes e úmidos, especialmente se não repõem nutrientes perdidos através da transpiração.

A insolação é o mais grave efeito nocivo do calor e corresponde à incapacidade do corpo humano reduzir a temperatura central com rapidez através da transpiração, podendo surgir lesões significativas em zonas terminais do corpo, como por exemplo, orelhas, nariz, etc. As consequências são mais graves, se o calor estiver associado a uma grande umidade. (Soares, Serra, \& Almeida, 2007, pp. 90-91).

Portanto, esse quadro pode ocorrer durante uma exposição prolongada ao calor seco. Assim, a temperatura corporal pode chegar a $43^{\circ} \mathrm{C}$ em função da ausência de transpiração, ocasionando, até mesmo, inconsciência (Cruz Vermelha Portuguesa, 1999).

Segundo Tavares $(2009$, p. 6), a fisiologia da exposição ao calor acontece "quando o indivíduo é submetido a uma sobrecarga térmica, é esse centro que comanda as alterações fisiológicas necessárias para conseguir o equilíbrio energético, preparando o organismo para aquela situação". Nesse sentido, explica ainda o autor: [...]

[...] quando o trabalhador é submetido a uma situação térmica em que recebe calor do ambiente em quantidade superior a capacidade do seu mecanismo termorregulador, ou que sua carga metabólica (energia) é dissipada sem tempo de reposição, o homem sofrerá danos a sua saúde, bem como a falta de líquidos, perdidos pela evaporação poderá trazer danos irreparáveis à sua integridade física (Tavares, 2009, p. 6).

Existem várias maneiras de um trabalhador adotar precauções quanto aos riscos provenientes de sua exposição ao calor, como, por exemplo, circular de vez em quando por local mais fresco ou local pré-estabelecido; reduzir seu ritmo ou sua carga de trabalho conforme seu turno ou afrouxar parte de suas roupas, sempre visando, entretanto, as normas vigentes de segurança no trabalho.

Além da submissão do operador à exposição ao calor, outros riscos, como superaquecimento no ambiente do trabalho e explosões, estão associados à operação de caldeira. Sendo assim, os operadores deverão receber treinamentos de acordo com a Norma Regulamentadora № 13 (NR-13) para operacionalidade desses equipamentos que são de vasos de pressão. Além disso, boas condições de operação e conservação devem ser asseguradas (Araújo, 1980). Ainda se deve considerar que, sendo um equipamento gerador de vapor, que, normalmente, fica em operação 24 horas por dia, qualquer deficiência na operação reduzirá a eficiência, acarretando prejuízos e retrabalhos operacionais.

\footnotetext{
1 Publicação periódica de circulação dirigida da Racco Equipamentos Ltda. Disponível em: www.racconet.com.br.
} 
É devido à presença desses riscos que, no Brasil, a NR-13, da Portaria MTB n. 3.214 de 1978 (Brasil, 1995) trata das normas de segurança na operação de caldeiras e vasos de pressão. Esta NR exige que os operadores de caldeira recebam treinamento de segurança na operação, com currículo mínimo contemplando assuntos como: noções de grandezas físicas e unidades; caldeiras - considerações gerais; operação de caldeiras; tratamento de água e manutenção de caldeiras; prevenção contra explosões e outros riscos; legislação e normalização.

O objetivo deste artigo é realizar uma análise na carga ambiental com a exposição ao calor do trabalho no setor de caldeira, visando a segurança e o bem estar para o trabalhador. Para isso, é necessário avaliar a exposição ocupacional ao calor, bem como feita as observações pertinentes no local de trabalho (Barazzutti, 2008). Apresenta-se a seguir o referencial teórico sobre a carga ambiental e as doenças causadas pela sobrecarga térmica. Posteriormente, são descritos os procedimentos metodológicos utilizados, onde foram realizadas pesquisas bibliográficas referentes às tarefas envolvidas no posto de trabalho na operação de caldeiras e suas exposições ao calor. Por fim, o artigo traz as conclusões obtidas com a realização desta pesquisa.

\section{Fundamentação Teórica}

De acordo com Tavares (2009), a carga ambiental [...]

[...] é o resultado da interação do homem com o ambiente, isto é, do calor proveniente da radiação e condução produzido por agentes ambientais, equipamentos, etc., e, o calor gerado pelo próprio homem, que representa a sua carga metabólica. A carga metabólica é o calor interno gerado pela atividade celular resultante do metabolismo basal, somado à energia térmica provenientes das atividades físicas (Tavares, 2009, p. 7).

Para ambientes industriais, Queiroz e Bastos (2005, p. 1, grifos dos autores), ressaltam: [...]

[...] onde os indivíduos estejam submetidos à condição de "stress" térmico pela exposição constante a fontes de calor e, onde, o tipo de atividade possa liberar agentes químicos, em forma de poeiras, vapores e partículas, a aplicação de uma avaliação corretiva, possibilita o controle de riscos para beneficiar a saúde e o conforto ambiental desses indivíduos.

Nas últimas décadas, através da conscientização e sensibilização, os profissionais da área de projetos das construções de edificações industriais têm adotado soluções simples, de baixo custo, e medidas que propiciam condições de higiene, segurança e bem-estar aos trabalhadores. Estas medidas são valorizadas no contexto da evolução de medidas governamentais, através de Normas Regulamentadoras, que visam uma qualidade ambiental do meio ocupacional e do entorno urbano, onde se inserem os edifícios. Essas soluções têm sido alvo de preocupações da classe empresarial, órgãos institucionais e profissionais envolvidos, de forma que se assegure também a eficiência dos serviços com tecnologia e a conservação de energia.

\subsection{Conceito de conforme térmico}

Segundo Lamberts (2012), o conforto térmico trata-se de uma sensação humana, subjetiva, que se relaciona a fatores físicos, fisiológicos e psicológicos, isto significa que [...]

[...] os fatores físicos determinam as trocas de calor do corpo com o meio, os fatores fisiológicos referem-se a alterações na resposta fisiológica do organismo, resultantes da exposição contínua a determinada condição térmica e finalmente os fatores psicológicos, que são aqueles que se relacionam às diferenças na percepção e na resposta a estímulos sensoriais, frutos da experiência passada e da expectativa do indivíduo (Lamberts, 2012, p. 4).

Os estudos realizados sobre o conforto térmico visam à análise e estabelecem condições necessárias para um ambiente com atividades e ocupação humana. Com estas condições, podem-se observar três fatores importantes:

a) A satisfação do homem e seu bem-estar confortável;

b) A performance humana, onde vários estudos mostraram que o desconforto de calor e frio reduz a performance humana; 
c) A conservação de energia não está muito articulada, pois a maioria do tempo o homem está em um ambiente condicionado artificialmente, onde há problemas de desperdícios de calefação e refrigeração (Lamberts, 2012, p. 4).

Também cabem situações variáveis pela variação biológica entre as pessoas, pois o correto é que todos os ocupantes do ambiente devem estar confortáveis termicamente.

\section{Metodologia}

Os procedimentos metodológicos tiveram como base uma revisão bibliográfica na análise das tarefas envolvidas no posto de trabalho na operação de caldeiras e suas exposições ao calor do trabalho. Desta forma, o estudo envolveu cinco etapas: análise da demanda; análise da tarefa; análise da atividade; diagnóstico e recomendações (Guérin et al., 2001 apud Iida, 2005).

Os procedimentos adotados foram os seguintes:

1. Estudo de Análise do Treinamento de Segurança na Operação de Caldeiras conforme NR 13;

2. Seleção de um local para realização do estudo: foi escolhida uma empresa do setor industrial no setor de caldeira à lenha localizada no Estado do Rio Grande dos Sul;

3. Entrevista com a técnica de segurança da empresa investigada, o que permitiu o conhecimento das prescrições referentes à função;

4. Entrevistas com os operadores das caldeiras da referida empresa;

5. Observações abertas e sistemáticas das atividades, inclusive com filmagens de algumas ações;

6. Levantamento das condições de riscos no setor em relação à exposição ao calor;

7. Reunião com os operadores para discussão e avaliação dos resultados do trabalho;

8. Avaliação dos dados coletados e elaboração de conclusões.

\subsection{Análise de demanda}

De acordo com Goulart e Silva \& Aguiar Moreira (2010, p. 5), [...]

[...] Programas são ações permanentes estabelecidas pela organização para atingir objetivos específicos, neste caso, o objetivo é a prevenção de acidentes e doenças do trabalho e, para isso a legislação brasileira e normas internacionais de Saúde e Segurança do Trabalho.

Nesta primeira etapa deve-se realizar uma análise documental. Desta forma, verificaram-se as condições ambientais referentes à exposição do calor. Além disso, nesta etapa, realizou-se uma entrevista informal com a técnica de segurança da empresa a ser estudada e com os funcionários da caldeira, a fim de levantar os principais problemas e queixas decorrentes da atividade.

\subsection{Análise de tarefa}

A NR-13 (Brasil, 1995), estabelece que, para ser considerado um operador de caldeira, é necessário possuir: [...]

Certificado de Treinamento de Segurança na Operação de Caldeiras, comprovação de estágio prático, possuir certificado de Treinamento de Segurança na Operação de Caldeiras, previsto na NR 13, aprovada pela portaria $n^{\circ} 02$ de 08.05 .84 ou ter experiência comprovada de pelo menos 03 (três) anos de experiência nessa atividade até 08 de maio de 1984 e ter concluído o $1^{\circ}$ grau.

A técnica de segurança nos apresentou a prescrição das tarefas a serem desenvolvidas, que estão detalhadas nos manuais dos fabricantes das caldeiras. Somos informados neste momento que os operadores foram treinados por um profissional de uma empresa credenciada junto ao Conselho Regional de Engenharia e Arquitetura (CREA). 


\subsubsection{Características da população}

A população investigada nesta pesquisa está assim distribuída:

Tabela 1. Características da população.

\begin{tabular}{|c|c|c|c|c|c|c|}
\hline Operador & Idade & Sexo & $\begin{array}{c}\text { Tempo de } \\
\text { Serviço no } \\
\text { Setor (anos) }\end{array}$ & $\begin{array}{c}\text { Experiência } \\
\text { Anterior na } \\
\text { Função }\end{array}$ & $\begin{array}{c}\text { Nível de } \\
\text { Instrução }\end{array}$ & $\begin{array}{l}\text { Participou de } \\
\text { Treinamento }\end{array}$ \\
\hline 01 & 32 & M & 07 & Não & $1^{\circ}$ grau & Não \\
\hline 02 & 37 & M & 12 & Sim & Superior & Sim \\
\hline 03 & 45 & M & 10 & Não & $2^{\circ}$ grau & Não \\
\hline 04 & 48 & M & 11 & Não & $1^{\circ}$ grau & Sim \\
\hline
\end{tabular}

Fonte: Elaborada pelos Autores.

\subsubsection{Características do ambiente do trabalho}

A caldeira está localizada em uma área de $600 \mathrm{~m}^{2}$. Sua estrutura é metálica com cobertura de alumínio com ventilação eólica. 0 piso é de concreto e possui duas aberturas laterais e uma porta metálica na frente. A iluminação do local durante o dia é natural e, à noite, é feita por 18 (dezoito) luminárias fluorescentes instaladas.

\subsubsection{Condições ambientais}

De acordo com observações e relatos dos operadores, a temperatura do ambiente é alta, especialmente no verão. Esta alta temperatura é provocada, principalmente, por vazamentos de vapor e mau isolamento das caldeiras.

O operador permanece a maior parte do tempo na sala do operador, onde há ar condicionado. A exposição ao calor não é constante, ocorre apenas quando o operador supervisiona os comandos e faz a manutenção dos equipamentos.

A ventilação é feita através de duas aberturas laterais e uma porta metálica na frente, que permanece aberta durante o horário de trabalho organizado em dois turnos: das $07 \mathrm{~h} 00 \mathrm{~min}$ às $19 \mathrm{~h} 00 \mathrm{~min}$ e das $19 \mathrm{~h} 00 \mathrm{~min}$ às $07 \mathrm{~h} 00 \mathrm{~min}$. A escala compreende uma rotação de doze horas de trabalho por 36 (trinta e seis) de descanso, com intervalo de uma hora para as refeições.

Nos finais de semana e feriados as caldeiras continuam ligadas, sendo desligadas no domingo à noite e religadas na manhã de segunda-feira.

\subsection{Análise das atividades}

A importância da realização da análise da atividade é de detectar características do trabalho efetivamente realizado e os mecanismos de adaptação e de regulação utilizados pelo operador.

\subsubsection{Descrição das atividades}

As atividades no setor de caldeiras são dividas em dois turnos. Observamos o turno das 07h00min às $19 \mathrm{~h} 00 \mathrm{~min}$ horas, durante toda a jornada. 0 operador chega às $07 \mathrm{~h} 00 \mathrm{~min}$ horas e desenvolve, durante sua jornada de trabalho, as seguintes manobras:

1. Olha o Livro de Ocorrências;

2. Ativa o quadro de disjuntores;

3. Aperta os fusíveis no painel de comando;

4. Liga o botão do tanque de serviço; 
5. Abre a válvula de circulação de óleo na entrada do aquecedor;

6. Abre a válvula de circulação de óleo na saída do aquecedor;

7. Liga o botão da bomba de óleo no painel de comando;

8. Aguarda o aquecimento do óleo;

9. Abre a válvula de passagem do óleo;

10. Abre a válvula do compressor de ar;

11. Abre a válvula de entrada do compressor de ar;

12. Liga o botão do compressor no painel de comando;

13. Aciona o botão de partida da caldeira no painel;

14. Aguarda o aumento da pressão do vapor;

15. Abre a válvula BY-PASS para circular vapor na rede;

16. Gerencia o funcionamento da caldeira em relação ao nível d'água, pressão do vapor, pressão do óleo, temperatura do óleo;

17. Quando necessário, faz o tratamento d'água de caldeira, utilizando produtos e recomendações de empresas especializadas;

18. Faz, a cada duas horas, a descarga de fundo;

19. Dá manutenção nas caldeiras quando não há técnico de manutenção.

A orientação da chefia é que as rotinas sigam as etapas constantes nos manuais dos fabricantes das caldeiras.

\subsection{Diagnóstico}

Como as atividades na caldeira são variadas, deve-se deixar que os operadores de caldeiras realizem suas funções diárias e não alterar sua dinâmica da realidade do trabalho. Sendo assim, Costa et al. (2011, p. 1), afirma que: "a produtividade é condicionada pelo conforto/desconforto percebida pela população, afetando assim diferentes áreas ocupacionais", como forma de diagnosticar diferentes áreas ocupacionais e atividades operacionais para fins de análise das condições de trabalho.

\subsection{Recomendações finais}

Para Sena (2004 apud Cruz Vermelha Portuguesa, 1999, s/n), "os extremos de temperatura ambiente, tanto o frio como o calor excessivos, podem provocar lesões em diversos tecidos do corpo. Se a exposição for prolongada, pode sobrevir a morte". 0 calor gerado pelas caldeiras é muito alto, provocando desconforto, o que foi visto in loco, mas não atingindo níveis capazes de provocar stress térmico, como prevê a NR-15.

O correto e recomendável é que sejam verificados os dutos e válvulas das caldeiras, eliminando os vazamentos de vapor existentes. 0 operador deve permanecer na sala a ele reservada, que possui ar condicionado, durante o tempo que não estiver executando tarefas diretamente nas caldeiras.

\section{Resultados}

Este trabalho tem o objetivo de mostrar as tarefas envolvidas no posto de trabalho na operação de caldeiras e suas exposições ao calor, através de análises e diagnósticos proporcionando o bem-estar do operador de caldeiras à lenha.

Sendo assim, os resultados em relação aos efeitos colaterais nos operadores de caldeiras à lenha, são citados por vários autores, que apresentam pesquisas e análises in loco sobre o posto de trabalho do operador. Para o desenvolvimento da temperatura ideal para o nosso corpo, Sena (2004, p. 1) expõe que: [...]

[...] as reações químicas desenvolvidas no nosso corpo atingem a sua eficácia máxima numa faixa estreita de temperatura, aproximadamente de $37,5^{\circ} \mathrm{C}$ - temperatura central. Para manter uma temperatura constante, o corpo precisa reter o seu calor quando a temperatura ambiente é baixa e perder calor quando o ambiente se torna quente. 
É por este motivo que devemos estudar o efeito do ambiente quente e a exposição ao calor para tarefas diárias do operador de caldeiras (Cruz Vermelha Portuguesa, 1999, p. 79).

\subsection{Efeitos do ambiente quente}

A Cruz Vermelha Portuguesa - CVP (1999) alerta que, normalmente, as pessoas que se exercitam em locais quentes e úmidos são afetadas pelo golpe de calor, especialmente quando descuidam da reposição do fluido e sais minerais que são perdidos por meio da transpiração. Já a "insolação pode ocorrer durante uma exposição prolongada ao calor seco. A temperatura do corpo pode subir até 43ㅇ C devido à impossibilidade de transpirar, ocorrendo por vezes inconsciência" (CVP, 1999, p. 80). Com estes efeitos sobre o corpo podemos verificar, na tabela abaixo, alguns sinais e sintomas de golpe de calor e da insolação.

Tabela 2. Efeitos no corpo.

\begin{tabular}{|l|l|}
\hline \multicolumn{2}{|c|}{ Golpe de Calor } \\
\hline Palidez & Congestionamento (pele vermelha) \\
\hline Arrefecimento corporal & Aumento da temperatura corporal \\
\hline Suores frios e viscosos & Pele seca \\
\hline Dilatação pupilar & Contração pupilar \\
\hline Dores de cabeça, cansaço, tonturas e náuseas & Dores de cabeça \\
\hline Ventilação rápida e superficial & Náuseas ou vômitos \\
\hline Pode surgir inconsciência & Ventilação rápida e profunda \\
\hline Cãibras (devido à desidratação) & A inconsciência pode sobrevir rapidamente \\
\hline & Agitação \\
\hline & Pulso forte e irregular \\
\hline
\end{tabular}

Fonte: Adaptado de Cruz Vermelha Portuguesa (1999).

São inúmeras as situações nas quais podem ocorrer estes sintomas, pois, quando exercermos qualquer atividade, o corpo libera calor e necessitamos dissipá-lo nas condições ambientais adequadas e com o corpo devidamente hidratado.

Outro fator importante são as alterações que podem surgir com a variação da temperatura sem vento e com uma boa condição de umidade.

Para este fato temos abaixo, algumas alterações conforme os efeitos na performance humana.

Tabela 3. Efeitos na performance humana.

\begin{tabular}{|c|c|}
\hline Temperatura ${ }^{\circ} \mathrm{C}$ & Efeitos na Performance \\
\hline 32,2 & \\
\hline 26,6 a 32,2 & $\begin{array}{l}\text { Esperar queixas universais, sério decréscimo da performance mental e } \\
\text { psicomotora e fadiga física. }\end{array}$ \\
\hline 26,6 & $\begin{array}{l}\text { Máximo para performance aceitável, mesmo de trabalho limitado; a produção de } \\
\text { trabalho reduzida em } 40 \% \text { a } 50 \% \text {; a maioria das pessoas sente secura nasal. }\end{array}$ \\
\hline 25,5 & $\begin{array}{l}\text { Decréscimo regular na performance psicomotora; os indivíduos experimentam } \\
\text { dificuldades em adormecer e manterem-se a dormir; ótima para tomar banho e } \\
\text { ducha. }\end{array}$ \\
\hline 23,8 & \\
\hline
\end{tabular}




\begin{tabular}{|c|c|}
\hline \multicolumn{2}{|l|}{22,2} \\
\hline 21,1 & $\begin{array}{l}\text { Ponto médio para conforto no verão; ótimo para tarefas exigentes em termos } \\
\text { visuais-motores. }\end{array}$ \\
\hline 19,9 & $\begin{array}{l}\text { Ponto médio para conforto no inverno (roupa muito pesada) e atividade } \\
\text { moderada, mas ligeira deterioração na resposta cinética; as pessoas começam a } \\
\text { sentir frio nas atividades sedentárias de interior. }\end{array}$ \\
\hline \multicolumn{2}{|l|}{18,8} \\
\hline \multicolumn{2}{|l|}{17,7} \\
\hline 15,5 & $\begin{array}{l}\text { A destreza das mãos e dos dedos deteriora-se, começa a ocorrer rigidez dos } \\
\text { membros e arrepios são positivos. }\end{array}$ \\
\hline \multicolumn{2}{|l|}{12,7} \\
\hline 9,9 & \\
\hline
\end{tabular}

Fonte: Estes efeitos de temperatura estão baseados com o ar relativamente parado e umidade normal (40\% a 60\%). Adaptado de American College of Sports Medicine - ACSM (1997).

Conforme Woodson (1981, p. 816) "as temperaturas mais elevadas são aceitáveis se a corrente do ar for incrementada e a umidade for diminuída (uma alteração de 0,6 a $2,2^{\circ} \mathrm{C}$ )".

\subsection{Prevenção}

Grande parte dos problemas de saúde decorrente do calor [...]

[...] pode ser prevenida ou seus riscos reduzidos e são eles na instalação de mecanismos técnicos de controle, certas práticas de trabalho, os períodos de trabalho e descanso, a aclimatação do calor e os operadores devem estar instruí-dos" (INFOSEG, Edição 10).

As seguintes precauções diminuem bastante os riscos gerados pelo calor:

- instalação de mecanismos técnicos de controle;

- certas práticas de trabalho;

- os períodos de trabalho e descanso;

- a aclimatação do calor;

- os operadores devem ser instruídos.

\subsubsection{A instalação de mecanismos técnicos de controle}

Através de estudos do local de trabalho, devemos elaborar um Plano de ventilação do ambiente como um todo e dimensionarmos medidas que promovam o resfriamento sobre as fontes do calor. As instalações de painéis de isolamento das fontes do calor radiante são medidas bastante positivas. Para serem mais eficazes, devemos proceder no resfriamento por evaporação e na refrigeração mecânica que são outras maneiras possíveis de redução do calor.

Outros equipamentos pode sem ser instalados, tais como ventiladores axiais, que são dispositivos que fazem reduzir o calor em ambientes quentes. 0 uso de Equipamento de Proteção Individual (EPI) adequado, conforme a Norma Regulamentadora №6 (NR-06), sobre roupas de proteção para o trabalhador, bem como a automação dos equipamentos, visando à redução do trabalho manual são outras formas de reduzir o calor.

\subsubsection{Certas práticas de trabalho}

Uma prática ideal para o operador de caldeiras em exposição ao calor é o consumo de água, conforme orientações médicas, um quarto de litro por hora. 
Também deve ser adotado como uma prática normal, é que os operadores recebam um treinamento em procedimentos de primeiros socorros para conhecerem as reações do excesso de calor no corpo humano, visando às atividades de cada operador de caldeira conforme suas condições físicas avaliadas por um médico.

\subsubsection{Os períodos de trabalho e descanso}

Os períodos de trabalho podem ser alternados com descanso mais prolongado, em que pausas podem ser realizadas nos períodos mais frescos do dia.

Assim, para melhores condições de trabalho e um período de descanso, os operadores de caldeira podem exercer atividades atribuídas com maior exposição ao calor.

\subsubsection{A aclimatação do calor}

Os operadores de caldeiras que são recém-contratados ou saíram de férias, ao retornarem ao trabalho, devem ter um treinamento de aprendizado e adaptação de cinco dias.

\subsubsection{Os operadores devem estar instruídos}

Os operadores de caldeiras e demais supervisores devem estar instruídos quanto à necessidade da ingestão de líquidos, sais perdidos durante a transpiração e perda de peso. Os treinamentos devem ser realizados por profissionais qualificados e cadastrados pelo Conselho Regional de sua área profissional, tendo em vista que todos que participam de atividades de exposição ao calor devem conhecer as reações iniciais dos sintomas da desidratação, esgotamento, desmaio, câimbras e insolação.

\section{Conclusão}

Este trabalho teve o objetivo de realizar uma análise da exposição ao calor do trabalho no setor de caldeira à lenha de uma empresa do setor industrial, com foco na análise da carga ambiental da atividade. Constatou-se que a exposição ao calor de grande expansão influencia doenças e, sendo assim, devem ser tomadas decisões preventivas conforme normas regulamentadoras NR-15 e NR-13, sobre a operação das caldeiras e suas atividades e operações insalubres.

Também através do diagnóstico, observamos que os operadores de caldeiras precisam de orientações sobre suas atividades diárias com prevenções de doenças afetadas pelo excesso de calor.

As doenças podem ser evitadas por meio de análises mensais de acidentes do trabalho, com estudos de causas e efeitos, em que podem ser identificados os problemas operacionais e estruturais dos processos de operação da caldeira.

Para fins de estudos e prevenções contra acidentes, as Normas Regulamentadoras NR-15 e NR-13 devem ser uma exigência obrigatória no início das operações das caldeiras, sendo ofertados, aos operadores, treinamentos anuais e de reciclagem de atividades de operações nas caldeiras de pequeno e grande porte em uma empresa do setor industrial.

\section{Referências}

American College of Sports Medicine (1977). ACSM.s health/fitnes facilitys tandards and guidelines (2nd ed.). Champaign: Human kinetics.

Araújo, J. L. (1980). Operação, controle e manutenção de caldeiras: curso básico. Rio de Janeiro: Cebrae/Ceag.

Associação Brasileira de Normas Técnicas (1992). NBR 5413: Iluminância de Interiores. Rio de Janeiro: ABNT.

Barazzutti, L. (2008). Laudo de Avaliação de Exposição ao Calor em Ambiente de Trabalho. Porto Alegre: s/e. 
Brasil. Ministério do Trabalho (1978). NR-13: Caldeiras, Vasos de Pressão e Tubulação [Redação dada pela Portaria MTb no 1.084, de 28 de setembro de 2017]. Disponível em: <http://trabalho.gov.br/images/ Documentos/SST/NR/NR13.pdf> - Acesso em: 21 nov. 2017.

Brasil. Ministério do Trabalho (1978). NR-15: Atividades e Operações Insalubres [Portaria MTb no 3.214, de 08 de junho de 1978]. Disponível em: <http://trabalho.gov.br/images/Documentos/SST/NR/NR15/NR-15.pdf> — Acesso em: 21 nov. 2017.

Brasil. Ministério do Trabalho (1978). NR-6: Equipamento de Proteção Individual - EPI [Texto dado pela Portaria SIT no 25, de 15 de outubro de 2001]. Disponível em: <http://trabalho.gov.br/images/Documentos/ SST/NR/NR6.pdf> - Acesso em: 21 nov. 2017.

Costa, E. Q. et al. (2011). Ambiente térmico quente e seu impacto na produtividade e sinistralidade. Porto [Portugal]: LAETA/FEUP.

Cruz Vermelha Portuguesa (1999). Manual de Socorrismo. Nem Martins: Editorial do Ministério da Educação.

Goulart e Silva, D. V., Aguiar, F. de, \& Moreira, I. S. (2010). Estudo da metodologia para avaliação, caracterização, medição e controle da exposição ocupacional ao calor. São Paulo: Unesp.

IIDA, I. (2005). Ergonomia: Projeto e Produção (2a ed.). São Paulo: Edgard Blücher.

Infoseg Edição 10. Publicação periódica de circulação dirigida da Racco Equipamentos Ltda. Disponível em: www.racconet.com.br.

Lamberts, R. (2012). Conforto e stress térmico. Florianópolis: Editora UFSC.

Queiroz. T. C. F de, \& Bastos, L. E. G. (2005). Riscos de exposição ao calor e circulação de poluentes em ambiente de trabalho industrial: método de análise em oficina de fundição naval. Rio de Janeiro: DARF/FAU/UFRJ.

Rosa, L. (2009). Operadores de caldeira à lenha e carga de trabalho. Porto Alegre: Editora UFRGS.

Ruas, A. C. (1999). Conforto térmico em ambientes de trabalho. Campinas: FUNDACENTRO, 1999.

Sena, P. (2004). Os efeitos do ambiente sobre o corpo humano. Rio de Janeiro: s/e.

Soares, R., Serra, L., \& Almeida, C. (2007). Saúde e Socorrismo 12 (pp. 90-91)[Curso Tecnológico de Acção Social $12 \stackrel{\circ}{\circ}$ Ano]. Porto Editora.

Tavares, M. (2009). Exposição ocupacional às temperaturas extremas. Belo Horizonte: Editora UFMG.

Woodson, W. (1981). Human factors design handbook. New York: McGraw-Hill. 